Bolton Hospice. Seamless care for patients is dependent on collaboration between these specialist services and community services provided by primary care and district nursing services.

Objective To improve services for palliative patients and those at end of life by implementing weekday community liaison meetings attended by the Hospice Liaison Nurse, Community Palliative Nurse Specialist, District Nurse neighbourhood representatives, AHPs, Social Worker and Community Consultant. Meetings are face-to-face and held at Bolton Hospice with a set agenda and prompt start and finish. Meetings typically last $30 \mathrm{~min}$.

Outcomes 160 patients were discussed in detail in the first six months of the project. Of these 113 died: 54 at home, 46 in the hospice, nine in hospital and two in residential or nursing homes. Meetings resulted in improved communication, decreased repetition of work, peer support, appreciation of alternative professional perspectives and care from the right professional at the right time. A number of patient stories illustrate the value of the meetings.

Discussion Daily community palliative care meetings can enhance communication and care for patients and may contribute to efforts to fulfil the wishes of patients and carers at end of life. This in turn may help to reduce unnecessary hospital admissions. The use of technology to facilitate remote attendance will improve efficiency and staffing costs. Improved IT and clerical support will allow communication of outcomes to other healthcare professionals such as out of hours services. Seven day liaison meetings may be implemented alongside further review of seven day specialist palliative care services.

\section{P-160 COMMUNITY PALLIATIVE CARE SPECIALIST NURSE 7- DAY SERVICE: DOES IT MAKE A DIFFERENCE?}

Claire Blakey, Jane Jones. Ashgate Hospicecare, Chesterfield, UK

\subsection{6/bmjspcare-2018-hospiceabs. 185}

Background The Community Palliative Care Specialist Nurse (PCSN) team identified challenges faced out of hours $(\mathrm{OOH})$, for patients, carers and health care professionals (HCP) with reported experiences of poor symptom management, carer distress and absence of specialist palliative care (SPC) support and advice.

These observations supported the Parliamentary and Health Service Ombudsman report (2015), that patients and carers 'suffered' due to difficulties accessing SPC OOH, concluding that; 'for the benefit of their comfort, dignity and wellbeing, all in need should have access to SPC services whenever they need it'. In response, the PCSN team implemented a service extension to seven days a week.

Aim To evaluate the PCSN service extension, explore outcomes and interventions, and evaluate patients', carers', HCPs' and PCSN team experiences.

Method The evaluation included analysis from a workshop review, staff focus groups, patient, carer and HCP feedback, data collection and analysis of activity and outcome data.

Results The following themes emerged from the evaluation analysis;

Improved symptom management - timely, proactive interventions and face-to-face assessments, with a focus on utilising specialist skills for patients in the unstable phase of illness
(Witt, de Wolf-Linder, Dawkins et al., 2013). Interventions contributed to reduced medication errors.

Place of care - patients remained at home, acute admissions avoided and appropriate hospice or hospital admissions facilitated.

Collaborative team work - improved external and internal working relationships.

Improved experience - feedback indicated feelings of reassurance, support and reduced anxiety.

Conclusion The evaluation has demonstrated improved patient, carer and HCP outcomes and experiences through access to a seven-day PCSN service. Additionally, evaluation supports national directives on access to seven-day SPC services as essential and offers experience into the challenges of delivering this within the community. Research is planned to further explore the effectiveness of PCSN interventions in improving patient outcomes.

\section{P-161 DOES HAVING A TRIAGE NURSE CHANGE OUR PRACTICE?}

Sharon Brown, Eiran Thomas. Severn Hospice, Telford, UK

10.1136/bmispcare-2018-hospiceabs. 186

Background Palliative care provision is becoming increasingly complex, and more of this care needs to be delivered within the community. Demands on our community Outreach Team are increasing; therefore new models of care are needed (Spencer, 2015).

Aim To assess the impact a triage nurse role would have on the quality of service delivered by the hospice outreach team.

Method (i) A time and motion study to capture the team's activities in a typical working week (ii) The secondment of an experienced nurse from the in-patient unit to work with the outreach team as a triage nurse (iii) The time and motion study was repeated two months following the introduction of the triage nurse role (iv) Evaluation of the new service was gained via questionnaires from hospice colleagues and members of the multidisciplinary team in the community.

Results Reduction of time spent on the telephone facilitated:

- Regular case reviews to prioritise care

- Opportunity to provide additional education

- Opportunity to explore research

- Recognised boost to staff welfare - able to have lunch/attend supervision.

Conclusion Triage is the process of prioritising patient care based on the severity and complexity of their situation and has been found to enable services to respond promptly to patient demand. Feedback from the questionnaires was universally positive.

Examples 'Really nice to hear a voice, not an answer phone' (Patient); 'Response is immediate, confident and knowledgeable and very helpful' (Social Worker).

This study has demonstrated that the addition of a triage nurse working with the hospice Outreach team has changed practice and enabled the beginnings of a uniformed, structured approach - enhancing channels of communication; developing professional relationships whilst being flexible enough to meet the ever-changing needs of the local population. 